\title{
The Effectiveness of Smartphone Temperature Sensors for Ambient Temperature Monitoring
}

\author{
Sonia Gavin ${ }^{1}$, Bobby Sidhu²
}

1 Lead author, B. Tech. Student, School of Health Sciences, British Columbia Institute of Technology

2 Supervisor, School of Heath Sciences, British Columbia Institute of Technology

\begin{abstract}
Background: Heat-related illness during extreme weather events is a leading cause of death and morbidity among vulnerable populations. Heat health alert systems are crucial in preventing serious impacts due to extreme heat, however its efficacy is limited by available atmospheric temperature data. A study was conducted to determine the accuracy of a silicon band-gap sensor integrated into certain models of smartphones when compared to a well-documented thermistor themperature sensor.

Methods: Ambient temperature readings were taken at a location chosen within Burnaby, $\mathrm{BC}$, using both a Met One sensor and a Sensirion sensor integrated into a smartphone. The data was then analyzed using a dependent T-test for paired samples to determine whether there was a significant difference between the grouped readings.

Results: According to the results of the dependent T-test with data adjusted to a calibration curve, it was determined that there was no difference between the readings taken by the Met One and the Sensirion sensors, $\mathrm{t}(30)=-0.68, \mathrm{p}=0.5(95 \% \mathrm{CI},-0.04$ to 0.02$)$.

Conclusions: Although further research is needed, the results of this study suggest that temperature sensors found in smartphones may be a smaller, lower-cost, and more accessible alternative to some of the higher-end models currently used to measure ambient temperature for the purposes of public health planning and policy-making.
\end{abstract}

Keywords: temperature, silicon band-gap, sensor, heat, Sensirion, Met One, smartphone, health

\section{INTRODUCTION}

Heat related illnesses lead to hundreds of premature deaths each year (Canadian Environmental Health Atlas, n.d). Typically, these deaths occur within the most vulnerable populations: the elderly, children under the age of 4, the chronically ill, and the socially disadvantaged (CDC, 2014; Health Canada,
2011). However, as our population ages, and people continue to move to large urban centers, more and more individuals may be at risk of adverse health effects due to heat. Studies predict that the annual number of extremely hot days in Canadian cities will double over the next 25 years and that the number of heat-related deaths will double by 2050 and triple by 2080 (Canadian Environmental Health Atlas, n.d.; Health Canada 
2011).

In face of these alarming statistics, health agencies have created resources for public health officials on how to manage the health risks associated with extreme heat (CDC, 2013; Health Canada, 2011). A heat health and alert response system is one way of assessing and communicating the risk to the public in real-time. However, in order to be effective, the alert protocol - which notifies officials of extremely hot weather conditions - needs to have accurate and readily available temperature data for the geographic location in question. Current weather monitoring sensors are often in fixed locations and do not take into consideration the microclimates that may exist in a complex urban environment. Moreover, the instrumentation used is generally expensive.

Recent advances in temperature monitoring devices, however, have opened up a new potential for remote temperature data to be collected in real-time, at a low cost, and with potentially high accuracy using small silicon temperature sensors. Unfortunately, little research has been done comparing the accuracy of such a device in the field compared to a sensor whose accuracy has been well documented. As such, the aim of the following study is to compare temperature readings taken from a silicon bandgap temperature sensor integrated into a smartphone with those from a Met One 064-2 thermistor. The topic was brought to the attention of the researcher by Dr. Sarah Henderson, senior scientist at the BCCDC and assistant professor at UBC.

\section{LITERATURE REVIEW}

\section{The Health Impact of Heat}

High temperatures are well known to have significant effects on the human body. In healthy adults, increased temperature can be dealt with by employing heat regulating mechanisms such as radiant, convective, conductive, and evaporative heat loss (Kovats \& Hajat, 2008; Hajat, 2010). However, vulnerable populations such as the elderly, the very young, and the chronically-ill, may have a reduced ability to regulate their body temperature, and as such may be more at risk of serious heat-related health consequences.

Even among these vulnerable groups, the elderly seem to account for the majority of the heatrelated deaths during periods of intense heat. According to a review by Åström et al., the elderly are significantly more at risk for cardiovascular and respiratory death than younger populations exposed to the same amount of heat (Åström et al., 2011). Moreover, this relationship seems to be consistent globally. Similarly, Haines et al. reports that the majority of excess deaths during heatwaves are elderly individuals (Haines et al., 2006). In their review, they attribute the majority of excess mortality during heatwaves to cardiovascular, cerebrovascular, and respiratory causes among the elderly. In addition, not only is this subsection of the population physiologically more susceptible to heat-related illnesses, but certain medications and mental disorders - such as dementia - can affect their perception of the risks associated with high heat ( $\AA$ ström et al., 2011). It follows, then, that the elderly are the major target group for heat-health awareness and warning initiatives.

Similar to the elderly, children also have a limited thermoregulating ability and are more susceptible to dehydration than healthy adults (Kovats \& Hajat, 2008). Despite this, however, studies have not shown an increased excess mortality rate for infants or children during major heat waves (Kovats \& Hajat, 2008). Although they would undoubtedly benefit from heat-health initiatives, 
they are not the primary group of concern.

People with existing medical conditions are also at a particularly high risk for developing longterm consequences from periods of elevated temperatures, and in some cases even death. People with cardiovascular, respiratory, or kidney diseases may see their conditions worsen (Kjellstrom et al., 2011). Similarly, people with multiple sclerosis, overweight individuals, and children with malnutrition may experience aggravated negative health effects already brought about by their condition (Kjellstrom et al., 2011).

It should be noted, that is it not simply vulnerable subsections of the population that will experience health effects due to elevated temperatures. Several studies have shown negative health effects in an otherwise healthy adult population due to extreme heat. These effects can be of varying severity. Among the milder consequences, a study of military troops who were deployed in hot, arid regions concluded that there was an increased incidence of kidney stones, likely due to dehydration and consequently a concentration of minerals in the urine (Kjellstrom et al., 2011). Heat strain is another - more severe - consequence of an elevated body temperature. An increase of one degree Celsius above the average core body temperature can produce this condition, leading to sluggishness and lack of concentration. If body temperature continues to increase, it can lead to unconsciousness, permanent organ damage, and death (Kjellstrom et al., 2011).

\section{Synergistic Factors}

The types and severity of health problems associated with periods of high heat can vary according to factors such as humidity, air pollution, mortality rates during the previous winter, and existing infrastructure. Increased humidity can intensify the effect of extreme heat and lead to higher morbidity and mortality in exposed populations (Haines et al., 2006). Similarly, air pollution can aggravate respiratory conditions which in turn exacerbates the effect of heat on pulmonary function. Not only is the effect of air pollution particularly harmful during periods of high heat, but air pollution may also worsen during heatwaves, which would account for the important increase of respiratory symptoms during these periods (Hajat, 2010; Kjellstrom et al., 2011). Interestingly, it has also been noted that when mortality rates are lower than average the preceding winter, there tends to be a particularly higher mortality rate due to heat during the summer (Åström et al., 2011). Finally, infrastructure plays a crucial role in predicting the impact of periods of high temperatures. During the 2003 European heat wave, for example, housing designed for cool summers was identified as one of the contributing factors for the particularly high heat-related mortality rate in France (Vandentorren, 2006). Therefore it is important to not only consider temperature when trying to determine the health impacts of heat. Although this study deals with temperature alone, there are several other factors that interplay to create - in some cases - a particularly harmful concoction. For some of the more vulnerable people in any given population, these factors can be deadly.

\section{Urban Heat Islands}

The presence of the heat-island effect in urban settings make the temperature profile of cities significantly different from that of rural communities. It has been observed that summer temperatures in the city can be on average 4.3 degrees Celsius higher than that of a rural community (Imhoff et al., 2010). In some 
instances, this can mean the difference between mild and severe heat-related symptoms.

In one study, researchers found that heat-related mortality increased significantly in the city center when compared to outer-lying communities (Tan, 2010). This relationship followed the heat-island gradient. Although there have been many studies assessing the differences between urban and rural temperatures, there has been little research done on the intra-city differences in temperature. In their study on urban heat islands using remote sensing techniques, Imhoff et al. highlight the need for higher-resolution spatial temperature mapping within cities in order to better characterize the impact of individual urban landscapes on the heat island effect (Imhoff et al., 2010). As such, low-cost, small, and remote temperature sensors could be of potential use to achieve a better picture of the spatial distribution of heat within cities. Moreover, with increased urbanization, heat-island effects play an increasingly large role in the health of individuals.

\section{Heat Health Warnings}

Most governments and health professionals acknowledge the need for preventative measures to reduce the health impacts of heat. While mitigating climate change and attenuating its effects are crucial as medium- to long-term solutions, there is a pressing need for widespread monitoring systems that can warn health agencies and the public of extreme heat. Following intense and impactful heatwaves, several countries and local governments have already put into effect heat warning systems. These systems share many of the same elements: temperature monitoring and weather forecasting, a means of relating temperature to increased health effects, and emergency response procedures (Pascal, 2006).
However, their effectiveness is highly variable depending on the means by which the risk is communicated (Toloo, 2013). Despite the fact that there have been criticisms of these systems' implementation, studies seem to suggest that the overall cost-benefit of such initiatives - if properly implemented - can be beneficial (Ebi, 2004; Toloo, 2013). It follows that a potential obstacle to its implementation, especially on smaller-scales and limited budgets, is costeffective and accessible temperature monitoring.

\section{Types of Sensors}

Great progress has been made in the past decade in electronic temperature sensors. Their small size, relatively low cost, and their ability to be integrated into existing electronic circuits have led developers to find new and innovative applications for these sensors. Depending on the application and desired output, there are several types of sensors available: thermocouple, resistance temperature detector (RTD), thermistor, and semiconductor temperature sensors [Table 1]. Thermocouple sensors have the largest range of any electronic temperature sensor. They are often selected because of their ability to function under extreme temperatures, however, due to the physical properties of the metals used, they are subject to a drift in readings over time (Ferreira, 2012; Kester, Bryant, \& Jung, 1999). This means that regular calibration is crucial to ensure accurate readings. Another limitation of the thermocouple sensor is that its output is not linear. This means that the interpretation of the device's output is more complex than a linear output and requires further processing. It should be noted, however, that thermocouple non-linearity has been well characterized, so it is only of minor concern. The second type of sensor is the RTD. It is more linear than a thermocouple sensor which gives it 
Table 1: Types of electronic temperature sensors and their respective characteristics

(Burlet, Vanbrabant, Piessens, \& Verheyden,2015; Kester et al., 1999; National Instruments, 2010)

\begin{tabular}{|l|l|l|l|l|}
\hline & Thermocouple & $\begin{array}{l}\text { Resistance } \\
\text { Temperature } \\
\text { Detector (RTD) }\end{array}$ & Thermistor & Semiconductor \\
\hline Widest Range $\left({ }^{\circ} \mathbf{C}\right)$ & $-270-2300$ & $-250-900$ & $-100-500$ & $-55-150$ \\
\hline Linearity & Low & Good & Satisfactory & Excellent \\
\hline Accuracy $\left({ }^{\circ} \mathbf{C}\right)$ & \pm 0.5 & \pm 0.01 & \pm 0.1 & \pm 0.25 \\
\hline Sensitivity & Low & Low & High & High \\
\hline $\begin{array}{l}\text { Calibration } \\
\text { Requirements }\end{array}$ & $\begin{array}{l}\text { Regular cold- } \\
\text { junction } \\
\text { calibration }\end{array}$ & $\begin{array}{l}\text { Regular } \\
\text { calibration }\end{array}$ & Regular calibration & $\begin{array}{l}\text { Very infrequent } \\
\text { calibration required } \\
\text { (low accuracy drift } \\
\text { over time) }\end{array}$ \\
\hline Cost & Low & High & Medium & Low \\
\hline Durability & $\begin{array}{l}\text { Usually durable } \\
\text { (material } \\
\text { dependent) }\end{array}$ & $\begin{array}{l}\text { Susceptible to } \\
\text { mechanical stress } \\
\text { and humidity }\end{array}$ & $\begin{array}{l}\text { Very susceptible to } \\
\text { mechanical stress } \\
\text { and humidity }\end{array}$ & Very durable \\
\hline
\end{tabular}

much more accurate readings and its temperature range is still quite large (Kester et al., 1999). However, an important limiting factor for its usage is its low sensitivity (Storr, 2015). The third type - thermistor sensors - have a more limited range and low linearity. They are, however, quite sensitive and relatively inexpensive, so these sensors are useful for measuring small changes in temperatures. Finally, semiconductor sensors are the best suited for use in ambient temperature monitoring. They are generally low cost, have good linearity and as a consequence good accuracy, as well as a range closer to what would be encountered in the environment (Ferreira, 2012; Kester et al., 1999). They also have the added benefit of requiring very little calibration during its lifespan; due to the stable crystalline structure of the silicon, very little drift in accuracy over time can be observed (Ferreira, 2012).

\section{Previous Research}

Researchers have used semiconductor sensors to monitor temperatures in wildlife studies, structural engineering, environmental analyses, and research into human health and comfort, to name a few (Barroca et al., 2013; Burlet et al., 2015; Chase, de Almeida, de Souza, \& da Costa, 2014; Hubbart, Link, Campbell, \& Cobos, 2005). They have also shown promise in the fields of art preservation, marketing, and electronic gaming (Lee, Angeles, Talampas, Sison, \& Soriano, 2008; Mayer \& Lechner, 2013). However, they are especially useful in applications that require small, low-cost, rugged sensors that can provide accurate data. Burlet et al. conducted experiments in several different environments and concluded that their silicon band-gap temperature sensor was a reliable, accurate, high-resolution, and also low-cost measuring device for long-term use (Burlet et al., 2015). In their study, the sensors not only withstood, but performed well in rugged environments; they were submerged in a turbulent stream for 28 days, and were placed in a cave for 27 days. Another study used a different silicon sensor and reached a similar conclusion (Angilletta \& Krochmal, 2003). In this study, the researchers submerged the sensors for one week in a water bath at $32^{\circ} \mathrm{C}$ and did not see any loss of accuracy from the beginning of the study to the end. They also buried several sensors $6 \mathrm{~cm}$ deep in soil at random sites and collected the data 75 days 
later. None of the sensors had failed and they all provided accurate temperature data.

Although there has been research conducted on the sensors themselves, at the time of this study no research exists on the accuracy of semiconductor temperature sensors integrated into smartphones.

\section{Mobile Devices}

Due to its greater suitability for monitoring environmental temperatures as they relate to human health, the following paper will focus on one type of semiconductor sensor: the silicon bandgap temperature sensor. This type has been incorporated into small circuits - known as integrated circuits (IC) - and included in certain models of smartphones. One such IC, the Sensirion SHTC1, is used in the Samsung Galaxy S4 and Note 3 and contains not only a silicon bandgap temperature sensor, but also a capacitive humidity sensor (Sensirion, 2013). Its temperature sensor has an accuracy of $\pm 0.3^{\circ} \mathrm{C}$ with a range of -30 to $100^{\circ} \mathrm{C}$. Meanwhile, its humidity sensor has an accuracy of $\pm 3 \% \mathrm{RH}$ and a range between $0-100 \%$ RH (Sensirion, 2013).

The company which developed the sensor also released the application program interface (API) which has allowed developers to create weather station apps for these phones (Mayer \& Lechner, 2013). While many of these apps are free, several designers have released "pro" versions which include features such as calibration for offsetting the impact of the device's battery, automatic logging of readings with geographic coordinates, and multi-day temperature graphing (A-Minor, 2014; Sensirion AG, 2014).

\section{Hand-held units}

In the past, hand-held weather station units have been used by emergency response crews, military organizations, outdoor enthusiasts, and other individuals who require accurate weather readings to protect their health and safety. They have also been used by scientists to measure outdoor ambient temperatures. The Met One 0642 is an example of a hand-held device that has been used and tested in the field. Its range and accuracy has been well-documented and it is currently considered a reliable tool for gathering weather data. The Met One 064-2 is a thermistor temperature sensor. It has a range of -50 to $50^{\circ} \mathrm{C}$, an accuracy of $\pm 0.1^{\circ} \mathrm{C}$ and does not measure humidity (Met One Instruments, 2010). While humidity is an important factor when determining the impact of heat and air quality on human health, due to time and budget constraints, the author will henceforth focus on the temperature monitoring capabilities of these devices.

\section{PURPOSE OF STUDY AND RESEARCH QUESTION}

The purpose of the present study is to compare temperature readings taken from a silicon bandgap temperature sensor integrated into a smartphone (the Sensirion SHTC1) with those from a Met One 064-2 thermistor.

The null hypothesis tested in this statistical analysis was that there was no difference between the means of the Met One and Sensirion data series. As such, the alternative hypothesis was that there was a difference between the means of the two.

\section{MATERIALS AND METHODS}

\section{Temperature Sensors}

For the purposes of this paper, the researcher used the Sensirion SHTC1 found in the Samsung Galaxy S4. Moreover, in order to take data readings with this sensor, the app called "Weather Station Pro" by A-Minor was used. The Met One 
064-2 was also used to compare the readings from the smartphone sensor. Table 2 summarizes both mobile and hand-held sensor ranges and accuracies.

\section{Solar Shielding}

In order to protect the Met One 064-2 from the effect of solar radiation on the air temperature readings, a solar shield was used. The radiation shield was designed specifically for this instrument and was also manufactured by Met One. However, because no such shield has been designed for the Samsung Galaxy S4, and because practically a shield may not impact the internal temperature of the device, no shield was used for the smartphone sensor. Instead, the devices were both placed in a sheltered location during the sampling period.

\section{Calibration}

While normally temperature sensors require regular calibration in order to provide accurate readings, silicon band-gap temperature sensors have a very low drift in accuracy over time. It is initially calibrated by the manufacturer and will remain so for long periods of time due to the relatively inert properties of silicon-based sensors, and an internal memory bank within the IC that stores calibration information (Ferreira, 2012; Ondrey, 2002). The smartphone used in this study was purchased new in October 2014 approximately four months before the start of the study. Because the smartphone was still quite new, there would have been negligible drift in accuracy from its factory calibration. Moverover, not only was it impractical to remove the sensor from the phone for calibration during the short run of this study, but it was also impossible to calibrate the sensor while inside the smartphone. As such, no calibration was performed by the researcher prior to data collection.

The Met One 064-2, however, is a thermistor temperature sensor, and as such needed to be calibrated prior to use. It was calibrated before data collection and verified against an Environment Canada temperature sensor at the UBC Research Forest in Maple Ridge (R. Tsin, personal communication, February 17, 2015).

\section{Pilot Study}

On February $4^{\text {th }} 2015$, a pilot study was conducted using the data collection method outlined below. Both temperature monitoring devices were left outside to acclimatize for one hour before 5 temperature readings were taken, each 20 minutes apart. The results of this pilot study were encouraging, and data collection for the purposes of the study began the following week.

\section{Data Collection}

Between February $4^{\text {th }}$ and $13^{\text {th }} 2015$, numerical temperature data was collected in the city of Burnaby, British-Columbia, Canada. Readings were taken simultaneously with the Met One 0642 and the Samsung Galaxy S4 at a sheltered

Table 2: Sensor model ranges, accuracies, and sizes

\begin{tabular}{|c|c|c|c|c|}
\hline & \multicolumn{2}{|c|}{ Sensirion SHTC1 } & \multicolumn{2}{|c|}{ Met One 064-2 } \\
\hline & Humidity & Temperature & Humidity & Temperature \\
\hline Range & $0-100 \% \mathrm{RH}$ & -30 to $100^{\circ} \mathrm{C}$ & & -50 to $50^{\circ} \mathrm{C}$ \\
\hline Accuracy & $\pm 3 \% \mathrm{RH}$ & $\pm 0.3^{\circ} \mathrm{C}$ & & $\pm 0.1^{\circ} \mathrm{C}$ \\
\hline Size & \multicolumn{2}{|c|}{$\begin{array}{l}2 \times 2 \times 0.75 \mathrm{~mm} \text { (sensor alone) } \\
13.5 \times 7 \times 0.7 \mathrm{~cm} \text { (smartphone) }\end{array}$} & \multicolumn{2}{|c|}{$3 \times 0.5 \times 0.5 \mathrm{~cm}$ (approximately) } \\
\hline
\end{tabular}


suburban location. The location was protected from both sun and wind with an overhang and a concrete wall [Figure 1]. This was done in order to minimize error due to wind chill and solar radiation. The Samsung Galaxy S4 was placed in a thin plastic produce bag in order to protect it from damage and dirt. Then, both the Samsung Galaxy S4 and the Met One 064-2 were placed on a flat surface next to each other at a maximum of two feet apart. Once the equipment was placed at the location, the sensors were given enough time for the temperature readings to stabilize before recording the values. This was done in order to increase the accuracy of the readings. Moreover, the manufacturer of the SHTC1 IC recommends it in their app upon start-up (Sensirion AG, 2014). A total of 31 readings - measured on average 11 minutes apart - were taken at that location over the course of 4 days.

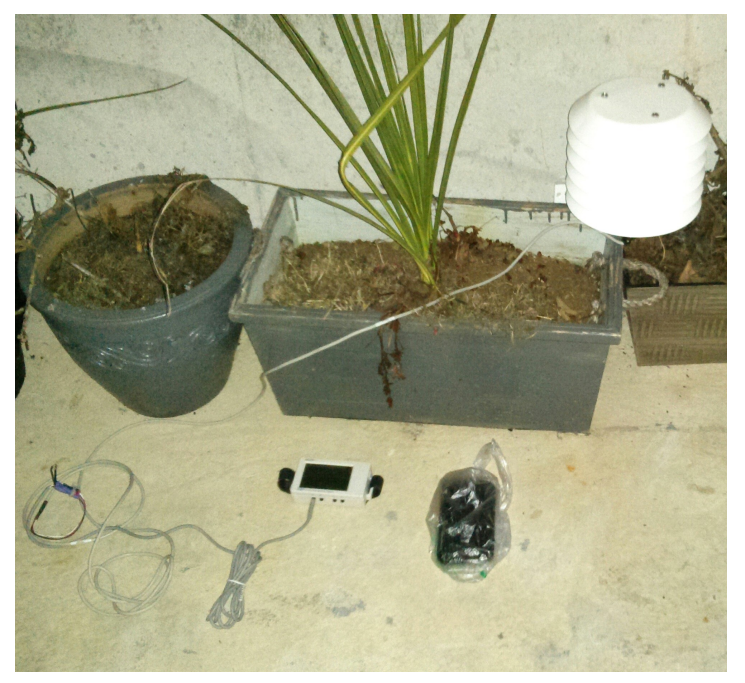

Figure 1: Photo of the sampling location set-up. Clockwise from top right: Met One 064-2 sensor with solar shield, Samsung Galaxy S4 phone in plastic bag, Met One data logger.

\section{Inclusion and Exclusion Criteria}

All temperature readings that had stabilized were included in the study. Temperature readings that continued to fluctuate were excluded because these were, by definition, inaccurate readings and did not represent the capabilities of the devices. Furthermore, upon analysis of the data, 3 data points were excluded because they were significant outliers; these were taken at the beginning of their respective days while the temperature sensors had not fully acclimatized yet.

\section{Reliability and Validity of Measures}

The Met One sensor used in this study is a welldocumented sensor that has shown good accuracy and sensitivity in the field for the study of environmental conditions. Consequently, it is a reliable and valid sensor upon which to compare the Sensirion SHTC1.

\section{Pre-Statistical Analysis}

Upon preliminary analysis, it was noted that there was a consistent difference between the data collected by the Met One 064-2 and the Sensirion SHTC1 for each data logging event. In the absence of any calibration on the part of the Sensirion SHTC1 or the app through which data readings were taken, it was assumed that the difference - which appeared to be steadily increasing - originated from that sensor. As such, the Sensirion's raw data was adjusted by a constant factor for each data logging event, and was termed "A_Sensirion". The value by which the data was either added or subtracted was calculated so as to be, on average, as close as possible to the Met One's range of temperature readings. A graph of the adjustment factors yielded a logarithmic function with a very good fit $\left(\mathrm{R}^{2}=0.991\right)$. Thus it is likely that one of the devices was drifting out of calibration during the course of the experiment. 


\section{RESULTS}

\section{Descriptive Statistics}

The numerical data collected during the study was first analyzed using OpenOffice Calc. Information such as the mean, median, range, and standard deviation was calculated. Parameters of note include the mean, median, and standard deviation for the Sensirion, which were all significantly higher than the MetOne and adjusted Sensirion values. The Sensirion data were also distributed over a larger range than the other data series. The complete results of these calculations can be found in Table 3.

Table 3: Descriptive statistics

\begin{tabular}{|l|c|c|c|c|c|}
\hline Variable & N & Mean & Median & Range & Std Dev \\
\hline Sensirion & 31 & 10.98 & 11.39 & $6.58-13.23$ & 1.84 \\
\hline MetOne & 31 & 10.09 & 10.26 & $7.84-11.19$ & 0.93 \\
\hline A_Sensirion & 31 & 10.10 & 10.64 & $7.88-11.23$ & 0.94 \\
\hline
\end{tabular}

In addition, the data was normally distributed, as verified by visual confirmation with a histogram [Figure 2] and by using the Shapiro-Wilk test. There were also no significant outliers.

\section{Inferential Statistics}

A dependent T-test conducted on the adjusted Sensirion SHTC1 values measured against the Met One 064-2 data. The test showed no significant difference between the two measuring devices $(\mathrm{t}(30)=-0.68, \mathrm{p}=0.5$, therefore the null hypothesis could not be rejected). The results from the test were also statistically significant (95\% CI, -0.04 to 0.02). The open-sourced statistical package PSPP was used to conduct the test.

\section{DISCUSSION}

The results of this study indicated that the adjusted temperature readings from the Sensirion silicon band-gap sensor did not differ significantly from the readings taken by the Met

One thermistor sensor. This would imply that the

\section{Difference Normality Curve}

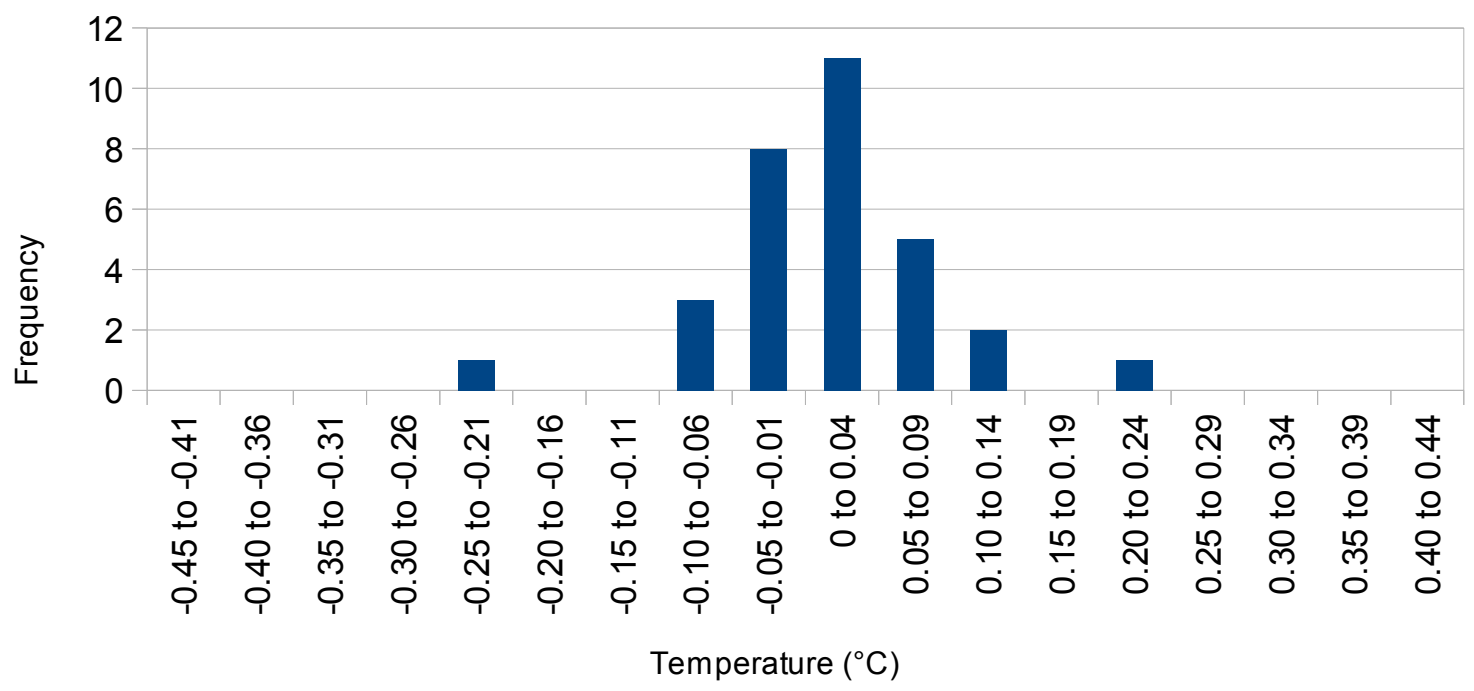

Figure 2: Histogram plot of the difference between A_Sensirion and MetOne data series 
temperature sensors found in smartphones may be as effective as some commonly used, larger, and more expensive sensors at measuring ambient temperature. At the time of this study there was no previous research conducted comparing smartphone ambient temperature senors with other types of ambient temperature sensors. However, theoretically, within the range of temperatures encountered in this study, both silicon band-gap and thermistor sensors have similarly high sensitivity (Burlet et al., 2015; Kester et al., 1999; National Instruments, 2010). Moreover, the Sensirion SHTC1 and Met One $064-2$ are both moderately accurate $\left( \pm 0.3^{\circ} \mathrm{C}\right.$ and $\pm 0.1^{\circ} \mathrm{C}$ respectively) (Met One Instruments, 2010; Sensirion, 2013). As such, the findings of this study would seem to agree with theoretical predictions. However, the effect of the smartphone casing material and the heat from the battery have yet to be studied. These factors may significantly impact the readings, and therefore require further study before definitive conclusions can be made.

If small temperature sensors integrated into smartphones can perform as well as those currently used - or with an acceptable degree of variation - temperature information may be gathered by health agencies, policy makers, and governments on a much larger scale wirelessly. This opens the possibility of creating finerresolution, real-time temperature mapping of complex urban environmental using wireless information gathered by the public. Not only would this allow for more data to be collected at a lower cost, but it could then be easily disseminated to stakeholders. For example, this data can be particularly useful for urban planners to identify literal "hotspots" that could benefit from heat-reduction measures. It could also be used by engineers when selecting building materials for a new urban development project. Another example would be creating mobile applications that can notify users of potentially hazardous heat conditions in their area. The application could even be tailored to particularly vulnerable or heat-sensitive populations complete with alerts and heat-health recommendations.

On a smaller scale, these smartphone sensors could be used to monitor ambient heat exposure on an individual basis. Since most people carry their smartphones wherever they go, this may be a useful tool in measuring the heat burden of the individual in question. It could also alert the person when the temperature rises to levels that could impact their health. This could be especially useful for elderly individuals who may not notice the heat as much as younger people (Åström, 2011).

Due to the Sensirion SHTC1's relatively low cost and simple interface through the smartphone, this sensor may also be valuable for research purposes. Studies that measure ambient temperature have typically relied on bulkier and more expensive sensors to take readings. Not only would it be physically easier to carry around a relatively small smartphone, but it could also directly transmit data to the internet or via a wireless connection (such as Bluetooth) to a computer.

\section{RECOMMENDATIONS}

Based on the findings of this study, the Sensirion temperature sensor would be suitable for the purposes of ambient temperature monitoring for public health applications. It would perform, within a statistically acceptable margin of error, similarly well as the Met One in detecting temperatures that could pose a threat to vulnerable populations. 


\section{LIMITATIONS}

Several limitations impacted the reliability of this study, and should be addressed in future studies. Of particular importance were the limitations imposed by the short time span and small budget of the study. For example, due to time pressures, the researcher was unable to gather a larger and more diverse sample set. A relatively homogenous set of data was collected and assumed to be representative of the ideal field conditions. However, it should be well understood by any reader that the ideal field conditions will very rarely be met, and yet temperature data will nonetheless need to be collected. Ideally the study would have taken place in many different types of locations exposed to sunlight, high humidity, wind, and radiant heat - to better assess the smartphone's sensor in a variety of conditions. As it stands, this study is limited in its capability to infer this sensor's performance under various different circumstances.

Another impact of this study's short time span was the availability of the equipment. Only certain periods of the day and week was the smartphone made available for the purposes of this study. This meant that more data points needed to be collected per data logging event and with shorter-than-anticipated intervals between temperature readings. This may have increased the impact of any error specific to a particular logging event.

Moreover, the acclimatization period for the Met One sensor was surprisingly long. The device was left outside to acclimatize for approximately one hour prior to data collection. In some cases this was not enough time judging by the steadily and continuously decreasing temperature readings observed by the device at intervals too high to be due to a natural decrease in temperature over the course of the day. The Met One sensor occasionally had to be left out for up to two hours before the readings stabilized and the experiment could be conducted. This greatly limited the amount of time that could be spent on data collection.

As previously mentioned, the effect of the smartphone's battery may have produced heat that interfered with the readings. The developers of the app used in this study have created an "experimental battery temperature based calibration for offsetting inaccurate ambient temperature and relative humidity readings" (AMinor, 2014). Although this feature was not used in this study, once perfected it should greatly reduce the amount of error due to the battery. Similarly, the casing may have affected the sensor's readings. The insulating effect of the casing material is unknown and as such it is possible it retained the heat generated by the battery, or buffered the sensor against variations in the ambient temperature. The colour of the smartphone itself may have an impact on the temperature readings. Although this study was conducted in a shaded area, in the field the smartphone may need to be exposed to sunlight and its dark colour may absorb more heat than other sensors, which are either light-coloured or protected from the sunlight using a solar shield. As such, this may be a potential source of error for future studies as well as in real-life applications. This could be easily countered using a solar shield specially designed for a smartphone, or by purchasing a white or lightcoloured model.

Finally, the smartphone's sensor readings were adjusted to account for what seemed to be sensor drift that closely followed a logarithmic function. Although unlikely, this phenomenon may not 
have been the result of sensor drift. One of the sensors might have been more influenced by humidity, for example, and daily fluctuations in humidity may have had an impact on its readings. Also, it was assumed that the drift originated from the Sensirion SHTC1 since the Met One 064-2 had been recently calibrated and tested against one of Environment Canada's temperature sensors. However, according to the research on sensor types, silicon band-gap sensors are much more resistant to drift over time than thermistor sensors. As such, of the two types, it is more likely that the Met One thermistor sensor was experiencing the drift. In order to correct for this, the Met One 064-2 should be calibrated before and after every logging event. Lack of time and resources prevented such frequent calibration for the purposes of this study.

\section{FUTURE RESEARCH}

This study used two different types of temperature sensors: thermistor and silicon bandgap. There are inherent differences between these two types of sensors, as noted in Table 1, that make them difficult to compare. Future studies should compare the silicon band-gap sensor found in smartphones with other types of silicon band-gap sensors more commonly used in environmental research - such as thermochron iButtons. This would allow for a better comparison between fundamentally similar sensors, and enable a more balanced evaluation of the smartphone as a temperature monitoring device. It would also help to evaluate the effect of the casing material and the heat generated by the battery of the smartphone. Future studies may also look at white- versus black-cased smartphone models, or the impact of a specially designed solar shield for smartphones to help negate the impact of solar radiation. The field of smartphone temperature monitoring is still young, and shows much promise for future research.

\section{CONCLUSION}

The present study used two temperature sensor types to measure ambient temperatures: the Met One 064-2 thermistor sensor and the Sensirion SHTC1 silicon band-gap sensor. Both sensors were placed in a sheltered location and were left to take a series of readings at regular intervals. Upon performing a correction for sensor drift, the researcher did not find any significant difference between the readings taken from a smartphone temperature sensor and those taken from the more studied and established temperature sensor: the Met One 064-2. Although further research is needed, the results of this study suggest that smartphones may be a smaller, lower-cost, and more accessible alternative to some of the higherend models currently used to measure ambient temperature for the purposes of public health planning and policy-making.

\section{ACKNOWLEDGEMENTS}

The authors would like to thank Sarah Henderson for providing the Met One used in this project, Harry Zhuang for being patient while his smartphone was being used for the purposes of science, and Robert Tsin for providing technical support for the Met One and data logger.

\section{ABBREVIATIONS}

$\mathrm{IC}=$ Integrated circuit

$\mathrm{RTD}=$ Resistance temperature detector

$\mathrm{RH}=$ Relative humidity

API $=$ Application program interface

\section{COMPETING INTERESTS}

The authors declare that they have no competing interests. 


\section{REFERENCES}

A-Minor. (2014).Weather Station Pro (Version

2.1.0.6) [Mobile application software].

Retrieved from:

https://play.google.com/store/apps/details

? $\mathrm{id}=$ com.aminor. weatherstationpro

Angilletta Jr, M. J., \& Krochmal, A. R. (2003).

TECHNIQUES-The Thermochron: A

Truly Miniature and Inexpensive

Temperature-Logger. Herpetological

Review,34(1), 31-32.

ASTM International. (2011). ASTM E563-11:

Standard Practice for Preparation and Use of an Ice-Point Bath as a Reference

Temperature. Retrieved from:

www.astm.org

Åström, D. O., Bertil, F., \& Joacim, R. (2011).

Heat wave impact on morbidity and mortality in the elderly population: a review of recent studies. Maturitas,69(2), 99-105.

Barroca, N., Borges, L. M., Velez, F. J., Monteiro, F., Górski, M., \& CastroGomes, J. (2013). Wireless sensor networks for temperature and humidity monitoring within concrete structures. Construction and Building Materials, 40, 1156-1166.

Burlet, C., Vanbrabant, Y., Piessens, K., Welkenhuysen, K., \& Verheyden, S. (2015). Niphargus: A silicon band-gap sensor temperature logger for highprecision environmental monitoring. Computers \& Geosciences, 74, 50-59.

Canadian Environmental Health Atlas. (n.d.). Heat Waves. Retrieved from: http://www.ehatlas.ca/climate- change/heat-waves\#footnote5 geu3zf7

Centers for Disease Control and Prevention. (2013). Climate Change and Extreme Heat Events. Retrieved from: http://www.cdc.gov/climateandhealth/pub s/ClimateChangeandExtremeHeatEvents.p $\underline{\mathrm{df}}$

Centers for Disease Control and Prevention. (2014). Climate Change: Extreme Heat. Retrieved from: http://ephtracking.cdc.gov/showClimateC hangeExtremeHeat.action

Chase, O. A., de Almeida, J. F. S., de Souza, J. R. B., \& da Costa Junior, C. T. (2014). Sensory platform architecture for IN SITU monitoring the thermal comfort in rural environments-The case study at Federal Rural University of Amazonian, Brazil. Measurement, 58, 294-300.

Ebi, K. L., Teisberg, T. J., Kalkstein, L. S., Robinson, L., \& Weiher, R. F. (2004). Heat watch/warning systems save lives: estimated costs and benefits for Philadelphia 1995-98. Bulletin of the American Meteorological Society, 85(8), 1067-1073.

Ferreira, J. (2012). Benefits of Silicon-Based Temperature Sensors. Quality Digest. Retrieved from: http://www.qualitydigest.com/inside/metr ology-article/benefits-silicon-basedtemperature-sensors.html

Haines, A., Kovats, R. S., Campbell-Lendrum, D., \& Corvalán, C. (2006). Climate change and human health: Impacts, vulnerability and public health.Public health, 120(7), 585-596.

Hajat, S., O'Connor, M., \& Kosatsky, T. (2010). 
Health effects of hot weather: from awareness of risk factors to effective health protection. The Lancet,375(9717), 856-863.

Health Canada. (2011). Communicating the Health Risks of Extreme Heat Events: Toolkit for Public Health and Emergency Management Officials. Retrieved from: http://www.hc-sc.gc.ca/ewhHYPERLINK "http://www.hcsc.gc.ca/ewh-semt/alt formats/hecssesc/pdf/pubs/climat/heat-chaleur/heatchaleur-eng.pdf"semt/alt formats/hecssesc/pdf/pubs/climat/heat-chaleur/heatchaleur-eng.pdf

Hubbart, J., Link, T., Campbell, C., \& Cobos, D. (2005). Evaluation of a low-cost temperature measurement system for environmental applications. Hydrological Processes, 19(7), 1517-1523.

Imhoff, M. L., Zhang, P., Wolfe, R. E., \& Bounoua, L. (2010). Remote sensing of the urban heat island effect across biomes in the continental USA. Remote Sensing of Environment, 114(3), 504-513.

Kester, W., Bryant, W. and Jung, W. (1999). Section 7: Temperature Sensors. In Practical Design Techniques for Sensor Signal Conditioning (pp. 7.1-7.39).

Kjellstrom, T., Butler, A. J., Lucas, R. M., \& Bonita, R. (2010). Public health impact of global heating due to climate change: potential effects on chronic noncommunicable diseases. International journal of public health, 55(2), 97-103.

Kovats, R. S., \& Hajat, S. (2008). Heat stress and public health: a critical review. Annu. Rev. Public Health, 29, 41-55.
Lee, A.M.C., Angeles, C.T., Talampas, M.C.R., Sison, L.G., and Soriano, M.N. (2008). MotesArt: Wireless Sensor Network for Monitoring Relative Humidity and Temperature in an Art Gallery [Abstract]. IEEE International Conference on Networking, Sensing and Control.

Mayer, F. and Lechner, M. (2013). Sensirion brings temperature and humidity sensors to the mobile phone. MEMS Trends, 15.

Met One Instruments. (2010). 060A-2, 062, T200A, 064 Data Sheet.

National Instruments. (2010). RTD, Thermistor, Thermocouple Comparison Chart. Retrieved from: http://digital.ni.com/public.nsf/allkb/C50F A55B3B2F85D9862572D00083350E

Neilsen-Kellerman Co. (n.d.). Kestrel Weather and Environmental Meters: Certificate of Conformity.

Ondrey, G. (2002). This digital humidity sensor requires no calibration. Chemical Engineering, 109(4).

Pascal, M., Laaidi, K., Ledrans, M., Baffert, E., Caserio-Schönemann, C., Le Tertre, A., ... \& Empereur-Bissonnet, P. (2006). France's heat health watch warning system. International Journal of Biometeorology, 50(3), 144-153.

Sensirion. (2014). Data Sheet SHTC1: Humidity and Temperature Sensor IC (Version 3).

Sensirion AG. (2014). Ambient Temperature and Humidity (Version 1.3) [Mobile application software]. Retrieved from: https://play.google.com/store/apps/details ? id=com.sensirion. . mbientsensing

Storr, W. (2015). Temperature Sensors. Retrieved 
from: http://www.electronics-

tutorials.ws/io/io $3 . \mathrm{html}$

Tan, J., Zheng, Y., Tang, X., Guo, C., Li, L., Song, G., ... \& Chen, H. (2010). The urban heat island and its impact on heat waves and human health in Shanghai. International journal of biometeorology, 54(1), 75-84.

Toloo, G. S., FitzGerald, G., Aitken, P., Verrall, K., \& Tong, S. (2013). Are heat warning systems effective. Environ. Health, 12.

Vandentorren, S., Bretin, P., Zeghnoun, A., Mandereau-Bruno, L., Croisier, A., Cochet, C., ... \& Ledrans, M. (2006). August 2003 heat wave in France: risk factors for death of elderly people living at home. The European Journal of Public Health, 16(6), 583-591. 